\title{
Relationship between placenta malaria and mother to child transmission of HIV infection in pregnant women in South East Nigeria
}

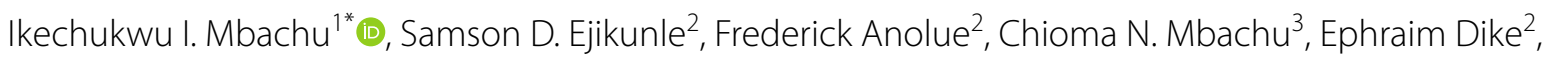
Eke Ejikem ${ }^{4}$ and Chijioke Okeudo ${ }^{2}$

\begin{abstract}
Background: This study determined the rate of mother-to-child transmission (MTCT) of HIV among HIV positive women with placenta malaria and factors associated with placenta malaria.

Methods: This was a prospective observational study of booked HIV positive pregnant women in labour. A smear for malaria parasite was made from blood taken from the placental tissue post-delivery. The baby HIV testing was done with DNA polymerase chain reaction at 6 weeks postpartum. Data on age, parity, gestational age, religion, address, highest educational attainment and knowledge about malaria prevention in pregnancy was obtained with questionnaires and analysed using SPSS version 20. The P-value was set at 0.05 providing a confidence interval of 95\%.

Results: A total of 174 booked HIV women participated in this study. The placental malaria parasitaemia prevalence was $44.8 \%$. Overall rate of MTCT of HIV infection was $17.2 \%$. Number of infants with HIV infection among women with maternal placental malarial parasitaemia was 30/78 (38.5\%), while it was 0/96 (0\%) for women without placenta malaria. There was significant relationship between placenta malaria density and infant HIV status (P-value $=0.001)$. The relative risk for MTCT of HIV for women with placenta malaria Density $>5000$ was $25 \%$ with $95 \%$ confidence interval of $11.41-54.76 \%$.
\end{abstract}

Conclusion: The mother-to-child transmission rate of HIV was high among HIV positive women with placental malaria parasitaemia. There is the need to review the malarial treatment and prophylactic measures at least in this group of women and to establish the nature of relationship between placenta malaria and MTCT of HIV infection.

Keywords: Placenta malaria, Mother to child transmission of HIV

\section{Background}

It is estimated that malaria and HIV infection directly or indirectly contribute to more than 4 million deaths per year [1]. In Africa HIV/AIDS is more prevalent in woman $(60 \%)[2-4]$. This translates into high prevalence

*Correspondence: imbachu@yahoo.com

${ }^{1}$ Department of Obstetrics and Gynecology, Nnamdi Azikiwe University, Nnewi Campus, Awka, Anambra, Nigeria

Full list of author information is available at the end of the article of vertical transmission of HIV infection in Africa [2, 3]. Mother-to-child transmission (MTCT) is by far the largest source of human immune deficiency virus (HIV) infection in children below the age of 15 year [5].

Malaria during pregnancy in sub-Saharan Africa, affects an estimated 24 million pregnant women; malaria prevalence, may exceed $50 \%$ among primigravid and secundigravid woman in malaria-endemic areas [6] and this has generated concern about the potential interactions with HIV infection, especially in sub-Saharan Africa

(c) The Author(s) 2020. This article is licensed under a Creative Commons Attribution 4.0 International License, which permits use, sharing, adaptation, distribution and reproduction in any medium or format, as long as you give appropriate credit to the original author(s) and the source, provide a link to the Creative Commons licence, and indicate if changes were made. The images or other third party material in this article are included in the article's Creative Commons licence, unless indicated otherwise in a credit line to the material. If material is not included in the article's Creative Commons licence and your intended use is not permitted by statutory regulation or exceeds the permitted use, you will need to obtain permission directly from the copyright holder. To view a copy of this licence, visit http://creativeco mmons.org/licenses/by/4.0/. The Creative Commons Public Domain Dedication waiver (http://creativecommons.org/publicdomain/ zero/1.0/) applies to the data made available in this article, unless otherwise stated in a credit line to the data. 
[7-9]. There is evidence that HIV infection appears to impair malarial immunity among pregnant women, as pregnant women infected with HIV demonstrate more frequent and higher density parasitemia than pregnant women not infected with HIV [7-10]. Other studies have also documented faster HIV disease progression and higher viral load among pregnant women with malaria infection. Several studies have documented the fetal complications of placental malaria parasitemia and the association between maternal HIV status and fetal outcome [11-15].

However, only few studies have explored potential role of malaria on MTCT of HIV infection especially in subSaharan Africa, where malaria and HIV are endemic. The observations from the few studies showed conflicting findings [16-22]. Ayisi et al. [20] in a study on maternal malaria and perinatal HIV transmission in Western Kenya noted that high density of placenta malaria is associated with increased risk of placenta malaria. However, Briand et al. [23] stated the need for further research on the impact of malaria on the clinical course of HIV and MTCT and antimalaria-antiretroviral interactions based on the conflicting reports by different researchers. Alemu also submitted that more studies will be needed to establish a clear relationship between malaria and MTCT of HIV infection [16]. The World Health Organization (WHO), in a recent paper on malaria and HIV, noted inconsistent results from studies assessing the impact of placenta malaria on MTCT of HIV infection and is calling for more research to shade more light on the impact of malaria on the natural history of HIV and potential therapeutic interactions. This study was carried out to determine the relationship between malaria placenta parasitaemia and MTCT of HIV in a tertiary health centre in Nigeria. It also evaluated the effect of prophylactic and therapeutic treatment of malaria on the placenta malaria density.

\section{Methods}

This was a prospective observational study among all booked HIV positive pregnant women in labour and their infants. This study was conducted over a 5-month period. This study was carried out in the labour ward of the Federal Medical Centre, Imo State, South-East of Nigeria. From December 2016 to March 2017. The centre offers free HIV voluntary counseling and testing, services as well as treatment, care and support of HIV positive patients. In addition, there is a modern laboratory facility equipped for appropriate diagnosis of endemic diseases and laboratory scientists trained in a current malarial diagnosis. The study was conducted among booked HIV positive pregnant women who presented to the labour ward and their infants.

\section{Inclusion criteria}

This included all booked HIV positive pregnant women in labour who consented to the study. The study excluded pregnant women who withheld consent or had major life-threatening opportunistic infection, pregnant women who presented in the third stage of labour and pregnant women who presented in labour but whose initial HIV screening was done outside the study facility.

\section{Sample size determination}

The minimum sample size needed to achieve a precision of $5 \%$ at $95 \%$ confidence level was determined [24] using the prevalence rate of placenta parasitaemia of $11.3 \%$ as documented by a study Inyang-Etoh et al. in Nigeria [25], to a minimum sample size of 170 . A total of 174 subjects were recruited and participated in the study. Patients who met the inclusion criteria and gave consent were recruited in the labour ward until the number of the sample was reached. The recruitment was from Monday to Sunday every week for the period of the study.

\section{Measure of outcome}

The main measure of outcome was the prevalence of placenta malaria and rate of mother to child transmission of HIV infection. The secondary outcome measures included relative risk of MTCT of HIV in women who had placenta malaria and factors significantly associated with presence of placenta malaria.

\section{Study procedure/methods}

Explanatory variables included age, parity, gestational age at booking, ethnicity, religion, educational status, occupation, use of IPT (sulfadoxine-pyrimethamine combination) for malaria in pregnancy, sleeping under insecticide-treated nets, use of HAART, CD4 counts, Episiotomy/perinatal tear, duration of rupture of membranes. The women are usually counseled after diagnosis in antepartum period for need for retesting in labour according to the national guideline of Nigeria on PMTCT of HIV. The counseling was reinforced by the researchers and assistants when they present in labour. Relevant information was entered into the question from the notes and any additional information was obtained from the patient on admission in labour ward. The parturient who fulfilled the inclusion criteria were recruited in labour ward. A standard obstetric care for HIV positive women in labour was strictly observed. A smear was made from the placental tissue post-delivery. The newborns were given prophylactic Nevirapine for 6 weeks. The infants were seen in 6 weeks postpartum for infant HIV testing 
using DNA PCR by collecting the dried blood sample (DBS).

\section{Placental blood aspiration techniques}

As used in the study by Sowunmi et al. [26] the fetal surface of the placenta was positioned upwards. A 21-gauge needle attached to a $5 \mathrm{ml}$ syringe was inserted through the whole thickness of the placental at its thickest point to measure its thickness. The needle was then withdrawn and the approximate thickness of the placental was determined. The needle was re-inserted at the same point such that its tip was placed at a level approximately below half the depth of the estimated placental thickness. The tip of the needle at this position was located in the maternal half of the placenta [27].

After withdrawal, the attached needle was carefully discarded into a sharp object box. Thick blood smear was prepared from placental aspirates and air dried. The smears were stained with freshly prepared $20 \%$ Giemsa maintained at a $\mathrm{pH}$ of 7.2 for $15 \mathrm{~min}$. The stain was rinsed off in buffered water and left to dry propped diagonally.

\section{Assessment of quality of blood smears and parasitaemia quantification}

The blood smears were examined by light microscopy at low $(\times 10)$ and high $(\times 100$ oil immersion $)$ magnifications.

The following parameters were assessed in the stained blood smears obtained by the technique: the count of asexual and sexual forms of Plasmodium falciparum and the presence or absence of malaria pigment granules. In positive smears, the number of asexual and sexual forms of $P$. falciparum in Giemsa-stained thick blood smears were counted against 1000 white blood cells assuming a normal count of 6000 leucocytes per microlitre of blood. A blood smear was declared negative if no parasite was found after examination of 100 microscope fields.

Calculation of parasite density for the positive films was by the formula below thus:

$$
\text { Number of parasites } \times 6000=\text { Parasites } / \mu \mathrm{L}
$$

\section{Infant HIV diagnosis}

All HIV exposed infants were tested for HIV using DNA PCR by collecting the dried blood sample (DBS) at the age of 6 weeks. The collected samples were sent to the Virology Department of Nnamdi Azikiwe University Teaching Hospital (NAUTH), Nnewi in Anambra State for DNA PCR testing.

\section{Disclosure of results}

The disclosure of result was done after counselling. Infants with confirmed HIV patients were referred to the paediatric infectious disease unit of the hospital for further evaluation and management.

\section{Results validation and interpretation}

HIV-1 DNA detected: when HIV-1 OD $>0.8$ (regardless of IC OD).

HIV-1 DNA not detected: when HIV-1 OD $<0.2$ and IC OD $>0.2$

Invalid: when $\mathrm{HIV}-1 \mathrm{OD}<0.2$ and IC $\mathrm{OD}<0.2$, needed retest.

Indeterminate: when HIV-1 OD was between 0.200 and 0.800 , and/or if HIV-1 + sample was in a well next to a positive control or if a new HIV-1 + sample was next to a well with a previously known HIV + sample, needed retest.

\section{Statistical analysis}

Statistical analysis of the result was done using SPSS version 20.0. There were cross tabulations to explore relationships between variables. The level of statistical significances was set at $\mathrm{P}$-value 0.05 providing $95 \%$ confidence interval. Risk estimate was done to determine the relative risk of MTCT of HIV infection among women with placenta malaria. The Chi square test was used to determine associations between the categorical variables while linear logistic regression was used to determine the independent risk factors for placenta malaria.

The ethical approval for this study was obtained from the institutional ethical committee (Imo State University Teaching Hospital, Orlu). The study was carried out in accordance with the Code of Ethics of the World Medical Association (Declaration of Helsinki) for experiments involving humans. Informed consent was obtained from all the participants.

\section{Results}

A total of 174 HIV positive pregnant women participated in this study. All the women received antiretroviral therapy. Seventy-eight (44.8\%) had placenta malaria and $30(17.2 \%)$ of the infants tested positive to HIV infection at 6 weeks. Table 1: shows the relationship between placenta malaria density and infant HIV status. There was significant relationship between placenta malaria density and infant HIV status (P-value $<0.001$ ). The number of infants with HIV infection among women with maternal placental malarial parasitaemia was $30 / 78$ (38.5\%), while it was $0 / 96(0 \%)$ for women without placenta malaria. Hundred percent $(100 \%)$ of the infants whose placental malaria density is more than five thousand $(>5000)$ are HIV positive while $96 \%$ whose placental malaria density were between 0 and 5000 were HIV negative and 4\%. The relative risk of developing HIV was $25 \%$ with confidence interval of $11.41-54.76 \%$ more in infants whose placental 
Table 1 Placental malaria and infant HIV status

\begin{tabular}{|c|c|c|c|c|}
\hline \multirow[t]{2}{*}{ Placental malaria parasite density } & \multicolumn{4}{|c|}{ Infant HIV status } \\
\hline & Positive & Negative & Total & P-value $=0.001$ \\
\hline 0 & 0 & 96 & 96 & \\
\hline $1-100$ & 5 & 25 & 30 & \\
\hline $101-1000$ & 0 & 8 & 8 & \\
\hline $1001-3000$ & 0 & 14 & 14 & \\
\hline $3001-5000$ & 1 & 1 & 2 & \\
\hline Greater or equal to 5001 & 24 & 0 & 24 & \\
\hline Total & 30 & 144 & 174 & \\
\hline
\end{tabular}

Table 2 Relative risk of MTCT of HIV in women with placental malaria

\begin{tabular}{|c|c|c|c|c|c|c|c|}
\hline Placental malaria & Infant HIV status & & Total & $x^{2}$ & P-value & RR & $95 \% \mathrm{Cl}$ \\
\hline & Negative & Positive & & 134 & $<0.01$ & $25 \%$ & $11.42-54.76$ \\
\hline$>5000$ & $0(0 \%)$ & $24(100 \%)$ & $24(100 \%)$ & & & & \\
\hline $0-5000$ & 144 (96\%) & $6(4 \%)$ & $150(100 \%)$ & & & & \\
\hline Total & $144(82.8 \%)$ & $30(17.2 \%)$ & $174(100 \%)$ & & & & \\
\hline
\end{tabular}

$R R$ relative risk, $\mathrm{Cl}$ confidence interval

Table 3 Placental malaria and sociodemographic variables

\begin{tabular}{lllll}
\hline Factors & \multicolumn{2}{l}{ Placental malaria (\%) } & $\boldsymbol{X}^{\mathbf{2}}$-value & $\boldsymbol{P}$-value \\
\cline { 2 - 3 } & $\mathbf{0 - 5 0 0 0}$ & $\mathbf{>} \mathbf{5 0 0 0}$ & & \\
\hline Age range & & 2.79 & 0.59 \\
$<20$ years & $1(0.67)$ & 0 & & \\
$20-24$ & $22(14.67)$ & $5(20.83)$ & & \\
$25-29$ & $56(37.33)$ & $5(20.83)$ & & \\
30-34 & $51(34.0)$ & $10(41.67)$ & & \\
35 years and above & $20(13.33)$ & $4(16.67)$ & & \\
Educational status & & & 6.09 \\
None & $3(2.0)$ & $1(4.35)$ & & \\
Primary & $6(4.0)$ & $2(8.7)$ & & \\
Secondary & $100(66.67)$ & $19(82.61)$ & & \\
Tertiary & $41(27.33)$ & $1(4.35)$ & & \\
Marital status & & & 7.20 & \\
Currently married & $144(96.0)$ & $23(95.83)$ & & \\
Divorced & 0 & $1(4.17)$ & \\
Separated & $1(0.67)$ & 0 & \\
Single & $4(2.67)$ & 0 & \\
Widowed & $1(0.67)$ & 0 & \\
\hline
\end{tabular}

malaria were more than five thousand $(>5000)$ than in infants whose placental malaria density are between 0 and 5000. The relative risk of mother to child transmission of HIV was $25 \%$. Table 2 shows the relative risk of MTCT of HIV infection.
The mean age of the women was $29.1 \pm 4.2$ year. Table 3 shows the association between social characteristics and placenta malaria density. There was no significant relationship between marital status and maternal placental malaria density $(\mathrm{P}$-value +0.13$)$.

Table 4 shows selected obstetrics characteristics and placental malarial density. Early gestational age at booking was associated with lower level of maternal placental malaria ( $\mathrm{P}$-value $<0.01)$. Maternal placental malaria rate at booking gestational age $<14$ weeks, $>14$ weeks and up to 27 weeks and $>28$ weeks were $47.4 \%$ (9 of 19) $45.5 \%$ (70 of 154 ) and $100 \%$ (1 of 1 ), respectively. There was an inverse relationship between CD4 count at booking and 36 weeks with the malaria placenta density with P-value of $<0.01$ and 0.01 , respectively.

There was a significant relationship between the use of ITN, malaria treatment/prophylaxis and placenta malaria density. Pregnant women who slept under insecticide-treated net during the pregnancy period were less likely to have placenta malaria $(\mathrm{P}$-value $=0.01)$. Women who received 3 doses of IPT during the period of antepartum period were less likely to have placenta malaria $(\mathrm{P}$-value $=0.04)$. Women who were treated for symptomatic malaria during antepartum period were less likely to have placenta malaria (P-value $<0.01)$. Table 5 shows malaria prevention/ treatment and placenta malaria density. The independent risk factors for placenta malaria include CD4 count at booking less than 350 and patients not treated for 


\begin{tabular}{|c|c|c|c|c|}
\hline \multirow[t]{2}{*}{ Factors } & \multicolumn{2}{|c|}{ Placental malaria (\%) } & \multirow[t]{2}{*}{$x^{2}$-value } & \multirow[t]{2}{*}{$P$-value } \\
\hline & $0-5000$ & $>5000$ & & \\
\hline Parity & & & 1.37 & 0.50 \\
\hline Para 1 & $44(29.33)$ & $8(33.33)$ & & \\
\hline Para 2-4 & $96(64.0)$ & $13(54.17)$ & & \\
\hline Para 5 and above & $10(6.67)$ & $3(12.5)$ & & \\
\hline Gestational age & & & 19.64 & $<0.01^{*}$ \\
\hline$<14$ weeks & $18(12.16)$ & $1(4.17)$ & & \\
\hline 14-20 weeks & $121(81.76)$ & $15(62.5)$ & & \\
\hline $21-27$ weeks & $8(5.41)$ & $8(33.33)$ & & \\
\hline 28-35 weeks & $1(0.68)$ & 0 & & \\
\hline \multicolumn{5}{|l|}{ Booking CD4 count } \\
\hline$<250$ & $5(3.33)$ & $4(16.67)$ & 15.06 & $0.01^{*}$ \\
\hline $250-350$ & $16(10.67)$ & $7(29.17)$ & & \\
\hline $351-500$ & $86(57.33)$ & $9(37.5)$ & & \\
\hline$>500$ & $43(28.67)$ & $4(16.67)$ & & \\
\hline CD4 count at 36 & & & 13.20 & $0.01^{*}$ \\
\hline$<250$ & $4(2.67)$ & $2(8.33)$ & & \\
\hline $250-350$ & $13(8.67)$ & $7(29.17)$ & & \\
\hline $351-500$ & $68(45.33)$ & $11(45.83)$ & & \\
\hline$>500$ & $65(43.33)$ & $4(16.67)$ & & \\
\hline
\end{tabular}

* Statistically significant

\begin{tabular}{|c|c|c|c|c|}
\hline \multirow[t]{2}{*}{ Factors } & \multicolumn{2}{|c|}{ Placental malaria (\%) } & \multirow[t]{2}{*}{$x^{2}$-value } & \multirow[t]{2}{*}{$P$-value } \\
\hline & $0-5000$ & $>5000$ & & \\
\hline Use of ITN & & & 7.67 & $0.01^{*}$ \\
\hline Yes & $120(80.0)$ & $13(54.17)$ & 7 & \\
\hline No & $30(20.0)$ & $11(45.83)$ & & \\
\hline IPT dose & & & 8.39 & $0.04^{*}$ \\
\hline 0 & $1(0.67)$ & 0 & & \\
\hline 1 & $6(4.0)$ & $1(4.17)$ & & \\
\hline 2 & $104(69.33)$ & $23(95.83)$ & & \\
\hline 3 & $39(26.0)$ & 0 & & \\
\hline Treatment of malaria & & & 144.30 & $<0.01^{*}$ \\
\hline Yes & 145 (97.32) & $24(100)$ & 144.30 & \\
\hline No & $4(2.68)$ & 0 & & \\
\hline
\end{tabular}

* Statistically significant

symptomatic malaria in pregnancy. This is shown in Table 6.

\section{Discussion}

The overall rate of mother-to-child transmission (MTCT) of HIV infection of $17.2 \%$ and placental malaria parasitaemia rate of $44.8 \%$ were recorded in this study. The rate of
MTCT among women with placenta malaria was $38.5 \%$. The rate of MTCT and prevalence of placenta malaria in this study are comparable to rates reported from some studies in other sub-Saharan African countries [28-32]. Ayisi et al. [20], recorded an overall rate of MTCT of HIV infection of $19.9 \%$ and $21.9 \%$ among women with placenta malaria which is lower than $38.5 \%$ in our study. However, Ayisi excluded women with low CD4 count and sick HIV patients which could have accounted for the observed difference. The placental malaria parasitaemia prevalence of $44.8 \%$ in this study is high compared to $25 \%$ to $26.4 \%$ in the studies done in Minna Nigeria, Burkina Faso and Gambia [33-36] but lower compared to $63.9 \%$ in a study in South East Nigeria by Umeh et al. [37]. The lower prevalence in Burkina Faso could be linked to the low prevalence of HIV infection in the country, This disparity in values in other part of Nigeria may be due to difference in endemicity and seasons at which the studies were conducted [38]. It was observed that placental malaria parasitaemia was significantly associated with MTCT of HIV. This result is consistent with some studies conducted in Uganda [29], Kenya [22], Malawi [30], and Tanzania [32].

Most patients who had symptomatic malaria and were treated with artemisinin-based combination therapy had low placental malaria parasitaemia and low rate of MTCT of HIV when compared with patients who had less than two doses of IPT for malaria with sulfadoxinepyrimethamine. There is urgent need to explore the role of artemisinin-based combination therapy (ACT) in reducing the placenta malaria and rate of MTCT of HIV infection. The use of anti-malarial medication is known to reduce HIV-1 replication and viral loads in adult [38, 39].

This study showed a significant difference in the rate of MTCT of HIV among the users of ITN and no users. This corroborates the use of ITN in all trimesters and all times advocated by the World Health Organization as one of the strategies for reduction of malarial burden in pregnancy [40]. This is consistent with a Cochrane review [41] which showed that in Africa, use of ITN compared with no nets significantly reduced placental parasitaemia. Though malaria prevention measures awareness was high in this study (98.8\%), the percentage use of ITN was $76.4 \%$. This may account for the high placental malarial parasitaemia in this study despite wide spread use of IPT for malaria.

The predictors of placental malarial parasitaemia and eventual MTCT of HIV infection in this study included, gestational age at booking, CD4 counts, treatment of symptomatic malaria with ACT and number of doses of IPT for malaria which are comparable to other studies $[22,41]$. However, the use of IPT was not an independent 
Table 6 Multiple linear regression model for predictors of placental malaria density

\begin{tabular}{|c|c|c|c|c|c|}
\hline \multirow{2}{*}{$\begin{array}{l}\text { Independent significant } \\
\text { factors }\end{array}$} & \multirow[t]{2}{*}{ Coefficient } & \multirow[t]{2}{*}{ Standard error } & \multirow[t]{2}{*}{$P$} & \multicolumn{2}{|c|}{ 95\% Confidence interval } \\
\hline & & & & Upper & Lower \\
\hline \multicolumn{6}{|l|}{ Gestational age (weeks) } \\
\hline$<14$ & 1 & 1 & 1 & 1 & 1 \\
\hline $14-20$ & 167.60 & 297.85 & 0.574 & -420.74 & 755.96 \\
\hline $21-27$ & -360.73 & 434.87 & 0.408 & -1219.73 & 498.26 \\
\hline $28-35$ & -329.80 & 1229.03 & 0.789 & -2757.49 & 2097.89 \\
\hline \multicolumn{6}{|l|}{ Booking CD4 count } \\
\hline $351-500$ & 1 & 1 & 1 & 1 & 1 \\
\hline$<250$ & 1639.69 & 712.70 & $0.023^{*}$ & 231.89 & 3047.49 \\
\hline $250-350$ & 1027.12 & 458.58 & $0.027^{*}$ & 121.29 & 1932.96 \\
\hline$>500$ & -52.89 & 306.05 & 0.863 & -657.45 & 551.65 \\
\hline \multicolumn{6}{|l|}{ CD4 count at 36} \\
\hline $351-500$ & 1 & 1 & 1 & 1 & 1 \\
\hline$<250$ & -1143.2 & 792.62 & 0.151 & -2708.87 & 422.47 \\
\hline $250-350$ & -821.94 & 511.78 & 0.110 & -1832.87 & 188.98 \\
\hline$>500$ & -308.30 & 291.46 & 0.292 & -884.04 & 267.42 \\
\hline \multicolumn{6}{|l|}{ Use of ITN } \\
\hline Yes & 1 & 1 & 1 & 1 & 1 \\
\hline No & 110.78 & 224.92 & 0.623 & -333.51 & 555.07 \\
\hline \multicolumn{6}{|l|}{ IPT dose } \\
\hline 3 doses & 1 & 1 & 1 & 1 & 1 \\
\hline 0 dose & 281.07 & 1216.53 & 0.818 & -2121.92 & 2684.07 \\
\hline 1 dose & -927.64 & 506.84 & 0.069 & -1928.80 & 73.51 \\
\hline 2 doses & 517.28 & 239.10 & $0.032^{*}$ & 44.98 & 989.58 \\
\hline \multicolumn{6}{|l|}{ Treatment of malaria } \\
\hline Yes & 1 & 1 & 1 & 1 & 1 \\
\hline No & 6357.33 & 283.13 & $<0.001^{*}$ & 5798.06 & 6916.60 \\
\hline
\end{tabular}

* Statistically significant

factor for placenta malaria. This calls for further studies and possible review of the strategies for malaria prevention among pregnant women with HIV infection. The high placental malaria parasitaemia prevalence and MTCT of HIV infection recorded in this study is unacceptable from the background of huge human and financial resources deployed into PMTCT of HIV.

One of the strengths of this study was that it evaluated the association between the placenta malaria density and MTCT of HIV infections. It was observed that women whose placenta has a malaria density greater than 5000 were 2.5 times more likely to transmit the virus to their offspring. The study also determined the effects of the prophylactic and therapeutic malaria drugs on placenta malaria density and MTCT transmission of HIV infection.

Despite the obvious strengths, the result should be interpreted with caution because it is a single centre study and cross-sectional study. Another limitation of this study was that it did not estimate the viral load, which has been shown to increase when the placenta malaria parasite density is very high. However, it documented the CD4 count which is used to monitor patients in many centres in developing countries. The study showed an inverse relationship between the CD4 count and the malaria parasite placenta density. This is consistent with the observation that malaria parasite affects the helper T-cells. The inability to assess the nutritional status was also another limitation of the study.

\section{Conclusion}

In view of the findings from this study, there is need to determine the resistance pattern of sulfadoxinepyrimethamine in this environment and to explore other alternatives for malaria prophylaxis in HIV positive pregnant women. It is hypothesized that ACT may be beneficial in reducing density of placenta malaria and MTCT of HIV infections in sub-Saharan Africa. More studies will be needed to establish the beneficial role of artemisininbased combinations as more effective drugs for IPT in 
reducing placental parasitaemia compared with currently used sulfadoxine-pyrimethamine for IPT. Optimizing the conditions of these women before pregnancy by reducing the viral load and increasing the CD4 count should be a potential target for reducing placenta malaria and mother to child transmission of HIV infection.

\begin{abstract}
Abbreviations
ACT: Artemisinin-based combination therapy; AIDS: Acquired immunodeficiency syndrome; CD4: cluster of differentiation 4; DBS: Dried blood sample; DNA: Deoxy ribonucleic acid; HIV: Immunodeficiency virus; IPT: Intermittent preventive treatment for malaria; ITN: Insecticide-treated net; HAART: Highly active anti-retroviral therapy; MTCT: Mother to child transmission; NAUTH: Nnamdi Azikiwe University Teaching Hospital; PCR: Polymerase chain reaction; PMTCT: Mother to child transmission of HIV infection; OD: Optical density; SPSS: Statistical package for social science.
\end{abstract}

\section{Acknowledgements}

The authors appreciate the support of the staff of Department of Obstetrics and Gynecology, Imo State University Teaching Hospital Orlu, Federal Medical Centre Owerri and Institute of Human Virology Laboratory, Nnamdi Azikiwe University Teaching Hospital, Nnewi.

\section{Authors' contributions}

The study arose from original ideas by ESD and MII while the study was designed by MII, ESD, AF and OC. The data collection and analysis were done by ESD, MII, MCN, EM and DE. The initial draft of the manuscript was done by ESD and EM with contributions from AF, MCN OC and DE while the initial draft was edited by MII. All authors read and approved the final manuscript.

\section{Funding}

There was no external funding. The authors bore the cost of the study.

\section{Availability of data and materials}

The datasets used and/or analysed during the current study are available from the corresponding author on reasonable request.

\section{Ethics approval and consent to participate in the study}

Ethical approval was sought and obtained before the commencement of the study at the study site. Informed consent was obtained from all the subjects before the commencement of the study.

\section{Consent for publication}

The study does not contain individual images, names or other identities of the participants. However, each participant gave consent for the publication of the findings of the study in a medical journal.

\section{Competing interests}

None of the authors has any conflict of interest.

\section{Author details}

${ }^{1}$ Department of Obstetrics and Gynecology, Nnamdi Azikiwe University, Nnewi Campus, Awka, Anambra, Nigeria. ${ }^{2}$ Department of Obstetrics and Gynecology, Imo State University Teaching Hospital, Orlu, Nigeria. ${ }^{3}$ Department of Paediatrics, Nnamdi Azikiwe University Teaching Hospital, Nnewi, Anambra, Nigeria. ${ }^{4}$ Department of Obstetrics and Gynecology, Abia State University Teaching Hospital, Aba, Nigeria.

Received: 28 August 2019 Accepted: 20 February 2020

Published online: 27 February 2020

\section{References}

1. UNAIDS/WHO. AIDS epidemic update. Geneva: UNAIDS/World Health Organization, 2004. Accessed on 20th of June 2015
2. UNAIDS/WHO. AIDS epidemics update. Geneva: UNAIDS/World Health Organization; 2009. unaids.org/pub/report/2009/jc1700-ep-updat e-2009-en.pdf. Accessed 22 June 2015.

3. The Power of Partnership. PEPFAR 2008 Annual Report to Congress. http://www.pepfar.gov/press/forth-annual-report/. Accessed 18 May 2015

4. WHO. Anti-retroviral drugs for treating pregnant women and preventing HIV infection in infants. HIV/AIDS Publication Guidelines. Geneva, World Health Organization, 2009. http://www.who.int/hiv/pub/guidelines/en/. Accessed 20th May 2015.

5. UNAIDS. Report on the Global AIDS epidemic 2012. Accessed 23 May 2015. http://www.unaids.org/publications/2012/76121/en.asp.

6. Steketee RW, Nahlen BL, Parises ME, Menendez C. The burden of malaria in pregnancy in malaria-endemic areas. Am J Trop Med Hyg. 2001;64(1-2 Suppl):28-35.

7. Steketee RW, Wirima JJ, Bloland PB, Chi Lima B, Mermin JH, Chitsulo $L$, et al. Impairment of a pregnant woman's acquired ability to limit Plasmodium falciparum by infection with human immunodeficiency virus type-1. Am J Trop Med Hyg. 1996;55:42-9.

8. Parise ME, Ayisi JG, Nahlen BL, Schultz LJ, Roberts JM, Misore A, et al. Efficacy of sulfadoxine-pyrimethamine for prevention of placental malaria in an area of Kenya with a high prevalence of malaria and human immunodeficiency virus infection. Am J Trop Med Hyg. 1998;59:813-22.

9. Verhoeff FH, Brabin BJ, Hart CA, Chimsuku L, Kazembe P, Broadhead RL. Increased prevalence of malaria in HIV-infected pregnant women and its complications for malaria control. Trop Med Int Health. 1999;4:5-12.

10. van Eijk AM, Ayisi JG, ter Kuile FO, Misore A, Otieno JA, Kolczac MS, et al. Human Immunodeficiency virus seropositivity and malaria as risk factors for third-trimester anaemia in asymptomatic pregnant women in Western Kenya. Am J Trop Med Hyg. 2001;65:623-30.

11. UNAIDS and NACA. Key statistics of HIV in Nigeria. Sbccvch.naca.gov. ng/2015-country-progress-report-nigeria-en.pdf. Accessed 21 May 2015.

12. Bloland PB, Wirima JJ, Steketee RW, Chilima B, Hightower A, Breman JG. Maternal HIV infection and infant mortality in Malawi: evidence for increased mortality due to placental malaria infection. AIDS. 1995:9:721-6.

13. Nielson KS, Melo M, Vanella I. Primary HIV infection during pregnancy: high rate of HIV-1 MTCT in a cohort of patients in South Brazil. Retrovirology. 2008;5:1

14. Naseem S, Anwar S, Ihsanullah M. Outcome and complications of malaria in pregnancy. Gomal J Med Sci. 2004;6:98-101.

15. Mockenhaupt FP, Frank P, Bedu-Addo G, Von Gaetner C, Boye R, Fricke K, et al. Detection and clinical manifestation of placenta malaria in Southern Ghana. Malar J. 2006;5:119.

16. Alemu V, Shiferaw Y, Addis Z, Mathewos B, Birhan W. Effect of malaria on HIV/AIDS transmission and progression. Parasit Vectors. 2013;6:18.

17. Centres for Disease Control. Interaction of HIV and malaria. Blantyre, Malawi (Victor Mwapasa, 10th CROI, Boston, 2003).

18. Ayisi JG. The effect of dual infection with HIV and malaria on pregnancy outcome in Western Kenya. AIDS. 2003;17:585-94.

19. WHO. Malaria and HIV interactions and their implications for Public Health Policy. Geneva: World Health Organization; 2004.

20. Ayisi JG, van Eijk AM, Newman RD, ter Kuile FO, Shi YP, Yang C, et al. Maternal malaria and perinatal HIV transmission, Western Kenya. Emerg Infect Dis. 2004;10:643-52.

21. Adeoti OM, Anumudu Cl, Nwuba Rl, Awobode HI, Olaniyan MF, Olayiwola $\mathrm{O}$, et al. Prevalence of HIV and malaria parasites co-infection in pregnant mothers and their babies post-delivery. Biol Agric Healthc. 2012;2:59-66.

22. Ayouba C, Badaut A, Kfutwah A. Specific stimulation of HIV-1 replication in human placental trophoblasts by an antigen of Plasmodium falciparum. AIDS. 2008;22:785-7

23. Briand V, Badaut C, Cot M. Placental malaria, maternal HIV infection and infant Morbidity. Ann Trop Paed. 2009;29:71-83.

24. Araoye MO. Research methodology with statistics for health and social sciences. Ilorin: Nathadex Publishers; 2003. p. 118-9.

25. Inyang-Etoh EC, Agan TU, Etuk SJ, Inyang-Etoh PC. The role of prophylactic antimalarial in the reduction of placental parasitaemia among pregnant women in Calabar, Nigeria. Niger Med J. 2011;52:235-8.

26. Sowunmi A, Abohweyere AEJ, Akindele JA, llesanmi AO, Falade CO, Oduola AM. Comparison of the incision and aspiration methods for diagnosis of placenta malaria infection. J Obstet Gynaecol. 1996;16:316-20. 
27. Regions used to interpret the complexicity of Nigeria. Geographical Alliance of lowa. University of Northern Lowa. http://www.uni.edu.gai/niger ia/background/standard5.html. Accessed 29 June 2015.

28. Wabwire-Mangen F, Gray RH, Mmiro FA, Ndugwa C, Abramowsky $\mathrm{R}$, Wabinga $\mathrm{H}$, et al. Placental membrane inflammation and risks of maternal-to-child transmission of HIV-1 in Uganda. J Acquir Immune Defic Syndr. 1999;22:379-85.

29. Brahmbhatt H, Sullivan D, Kigozi G, Askin F, Wabwire-Mangen F, Serwadda D, et al. Association of HIV and malaria with mother-to-child transmission, birth outcomes and child mortality. J Acquir Immune Defic Syndr. 2008:47:472-6.

30. Mwapasa V, Rogerson SJ, Molyneux M, Abrams E, Kamwendo D, Lema $V$, et al. The effect of Plasmodium falciparum malaria on peripheral and placental HIV-1 RNA concentrations in pregnant Malawian women. AIDS. 2004;18:1051-9.

31. John GC, Nduati RW, Mbori-Ngacha DA, Richardson BA, Panteleeff D, Mwatha A, et al. Correlates of mother-to-child HIV-1 transmission: association with maternal plasma HIV-1 RNA load, genital HIV-1 RNA shedding and breast infections. J Infect Dis. 2001;183:206-12.

32. Inion I, Mwanyumba F, Gaillard P, Cohan V, Verhofstede C, Claeys P, et al. Placental malaria and perinatal transmission of human immunodeficiency virus type 1. J Infect Dis. 2003;188:1675-8.

33. Omalu ICJ, Mgbemena C, Mgbemena A, Anyanwale V, Olayemi IK, Lateef $A$, et al. Prevalence of congenital malaria in Minna, North Central Nigeria. J Trop Med. 2012;2012:e274142.

34. Quedraogo A, Tiono AB, Diarra A, Bougouma ECC, Nebie I, Konate AT, et al. Transplacental transmission of Plasmodium falciparum in highly malaria endemic area of Burkina Faso. J Trop Med. 2012;2012:e109705.
35. McGregor IA, Wilson ME, Billewicz WZ. Malaria infection of the placenta in the Gambia West Africa; its incidence and relationship to stillbirth, birthweight and placental weight. Trans R Soc Trop Med Hyg. 1983;77:232-44.

36. Bulmer JN, Rasheed FN, Francis N, Morrison L, Greenwood BM. Placental malaria. 1. Pathological classification. Histopathology. 1993;22:211-8.

37. Umeh UA, Obi SN, Onah HE, Ugwu EOV, Ajah LO, Umeh CR, et al. The impact of intermittent preventive treatment with sulphadoxinepyrimethamine on the prevalence of malaria parasitaemia in pregnancy. Trop Doct. 2012;42:133-5.

38. Savarino A, Gennero L, Chen HC, Serrano D, Malavasi F, Boelaert J, et al. Anti-HIV effects of chloroquine: mechanisms of inhibition and spectrum of activity. AIDS. 2001;15:2221-9.

39. Savarino A, Gennero L, Sperber K, Boelaert JR. The anti-HIV-1 activity of chloroquine. J Clin Virol. 2001;20:131-5.

40. A Strategic Frame work for Malaria Prevention and Control during pregnancy in the African subregion, WHO Regional Office for Africa, Brazzaville, The Republic of Congo 2004. http://www.who.orgAFR/MAL/ O4/01. Accessed 15th Apr 2015.

41. Pryce J, Richardson M, Lengeler C. Insecticide-treated nets for preventing malaria. Cochrane Database Syst Rev. 2018;2018(11):CD000363. https:// doi.org/10.1002/14651858.CD000363.pub3.

\section{Publisher's Note}

Springer Nature remains neutral with regard to jurisdictional claims in published maps and institutional affiliations.
Ready to submit your research? Choose BMC and benefit from:

- fast, convenient online submission

- thorough peer review by experienced researchers in your field

- rapid publication on acceptance

- support for research data, including large and complex data types

- gold Open Access which fosters wider collaboration and increased citations

- maximum visibility for your research: over 100M website views per year

At BMC, research is always in progress.

Learn more biomedcentral.com/submissions 